\title{
THE MICROWAVE SPECTRUM AND STRUCTURE OF PROPYLENE OXIDE
}

\author{
M. IMACHI and R. L. KUCZKOWSKI
}

Department of Chemistry, University of Michigan, Ann Arbor, Michigan 48109 (U.S.A.)

(Received 12 May 1982)

\begin{abstract}
The $r_{\mathrm{s}}$ and $r_{0}$ structural parameters have been determined for propylene oxide from rotational constants for 16 isotopic species. The heavy-atom $\left(r_{0}\right)$ parameters are: $r\left(\mathrm{C}_{1} \mathrm{C}_{2}\right)$ $=1.470(3), r\left(\mathrm{C}_{2} \mathrm{C}_{3}\right)=1.505(2), r\left(\mathrm{C}_{1} \mathrm{O}\right)=1.441(2), r\left(\mathrm{C}_{2} \mathrm{O}\right)=1.435(3) \AA, \angle \mathrm{OC}_{1} \mathrm{C}_{2}=59.1(2)$, $\angle O \mathrm{OC}_{2} \mathrm{C}_{1}=59.4(1), \angle \mathrm{C}_{1} \mathrm{OC}_{2}=61.5(2), \angle \mathrm{C}_{1} \mathrm{C}_{2} \mathrm{C}_{3}=121.7(2), \angle O \mathrm{OC}_{2} \mathrm{C}_{3}=116.1(2)^{\circ}$. The methyl group torsional angles with the ring are: $\tau\left(\mathrm{C}_{1} \mathrm{C}_{2} \mathrm{C}_{3} \mathrm{H}_{9}\right)=24.7(8)$ and $\tau\left(\mathrm{OC}_{2} \mathrm{C}_{3} \mathrm{H}_{9}\right)$ $=-44.0^{\circ}(5)$. These parameters agree closely with analogous results for ethylene oxide.
\end{abstract}

\section{INTRODUCTION}

The microwave spectrum of propylene oxide (methyl oxirane) was first studied by Herschbach and Swalen [1]. Transitions from the three singly substituted ${ }^{13} \mathrm{C}$ isotopic species were subsequently assigned by Creswell and Schwendeman [2]. These authors reported the substitution values for the $\mathrm{C}-\mathrm{C}$ distances and the $\mathrm{C}-\mathrm{C}-\mathrm{C}$ angle. They also estimated $r_{0}$ values for the heavy-atom parameters based on appropriate assumptions to locate the hydrogen atoms.

It was necessary for us to assign the MW spectra of various deuteriumlabeled species of propylene oxide in order to study the stereochemistry about the double bond upon conversion of propylene to propylene oxide over catalysts [3] . This motivated us to also assign the readily prepared ${ }^{18} \mathrm{O}$ and $-\mathrm{CH}_{2} \mathrm{D}$ species in order to obtain a data set with single isotopic substitu tion at every position. Hence optimal data are available for structure evaluation including an insight into the orientation of the methyl group. The spectral and structural data are reported herein.

\section{EXPERIMENTAL}

Isotopic samples were prepared by epoxidation of propylene $(\mathrm{PR})$ to propylene oxide (PRO), either stereospecifically about the double bond using $m$-chloroperoxybenzoic acid [4] or with about $90 \%$ stereo randomization via heterogeneous oxidation over a silver catalyst [3]. The former method 
was employed for $(E)-\mathrm{PR}-1,2-\mathrm{d}_{2}$ [98\% $(E)-\mathrm{d}_{2}$, Merck, Sharp and Dohme Co.],

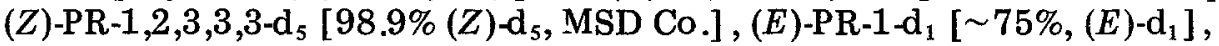
PR-2-d 1 ( $>99 \%, 2-d_{1}$ MSD Co.) and PR-3-d $\left(\sim 95 \%, 3-d_{1}\right)$. The latter method was also employed for the three stereolabeled propylenes above as well as for normal propylene with ${ }^{18} \mathrm{O}_{2}\left(99 \%,{ }^{18} \mathrm{O}, \mathrm{MSD}\right.$ Co. $)$ in the mixture. $(E)$-PR-1-d was prepared by hydroboration of methyl acetylene with 9-BBN followed by hydrolysis with $\mathrm{CH}_{3} \mathrm{COOD}$ [5], while PR-3-d was obtained by reaction of allyl chloride with $\mathrm{Zn}$ followed by acetic anhydride and $\mathrm{D}_{2} \mathrm{O}[6]$. This latter method was also used to prepare PRO containing a low ${ }^{13} \mathrm{C}$ enrichment $(\sim 13 \%)$ at $\mathrm{C}_{1}$ and $\mathrm{C}_{3}$ in order to check the assignments of an earlier study [2]. The reported ${ }^{13} \mathrm{C}_{1}$ and ${ }^{13} \mathrm{C}_{3}$ transitions were suitably enhanced and no change in the assignment was necessary ${ }^{13} \mathrm{C}$ enriched allyl chloride was prepared by adding $\mathrm{H}_{2}^{13} \mathrm{CO}(\sim 90 \%$, MSD Co.) to the Grignard of vinyl bromide followed by hydrolysis to allyl alcohol and conversion with $\mathrm{HCl}$ to allyl chloride [7].

All spectra were obtained with a Hewlett-Packard 8460A microwave spectrometer in the range 18-40 GHz using Stark modulation. Frequency measurements were accurate to at least $\pm 0.05 \mathrm{MHz}$.

\section{SPECTRAL ASSIGNMENTS}

The assignments were readily made with the aid of predicted spectra calculated from the structure in ref. 2 and verified by the observation of the correct Stark shift and from line intensity comparisons. Small splittings due to the methyl torsion were observed for a limited number of transitions consistent with the expected values from the molecular constants reported in ref. 1 . Several $a$ and $b$ dipole, $Q$ and $R$ branch transitions with $J \leqslant 18$ were assigned. Seven or eight low $J$ transitions were chosen to determine the rotational constants for the structure calculation because these were used for the analyses of the parent and ${ }^{13} \mathrm{C}$ species [2]. This choice was made in order to minimize the effect of centrifugal distortion. These transitions for the 11 isotopic species assigned in this study are listed in Table 1 . The moments of inertia are listed in Table 2 along with the previously determined values for the normal species, the three ${ }^{13} \mathrm{C}$ species and PRO-1,1-d which was reported elsewhere [8].

\section{STRUCTURE CALCULATION AND DISCUSSION}

It is possible to calculate the substitution coordinates ( $a_{\mathrm{s}}$ etc.) for all the atoms using the single substitution formulae derived by Kraitchman [9]. These values are listed in Table 3 and the derived structure is given in Table 4. One coordinate, viz. $b$ for $\mathrm{H}_{7}$ (see Fig. 1 for atom numbering), was very small and in fact Kraitchman's equations gave an imaginary value. Consequently, it is set at zero in Table 3. It is noted that nine other coordinates are below $0.20 \AA$. Vibration -rotation interactions are known to be troublesome when 
TABLE 1

Observed frequencies $(\mathrm{MHz})$ of the low $J$ transitions for propylene oxide isotopic species

\begin{tabular}{|c|c|c|c|c|c|c|}
\hline & ${ }^{18} \mathrm{O}$ & $5-d_{1}^{b}$ & $6-d_{1}$ & $7-d_{I}$ & $8-d_{1}$ & 9-d ${ }_{1}$ \\
\hline \multirow[t]{2}{*}{$\begin{array}{l}2_{20}-2 \\
2_{21}-2_{12} \\
3_{21}-2_{20} \\
3_{22}-2_{21} \\
3_{03}-2_{02} \\
3_{12}-2_{11} \\
3_{21}-3_{12} \\
3_{22}-3_{13}\end{array}$} & $\begin{array}{l}32443.84(4)^{\mathrm{a}} \\
\quad- \\
37235.48(-8) \\
37075.85(-2) \\
36916.23(6) \\
38210.85(4) \\
31468.52(-4) \\
35910.20(-1)\end{array}$ & $\begin{array}{l}30095.23(8) \\
32262.37(-1) \\
37153.45(10) \\
36998.24(3) \\
36842.90(3) \\
38076.28(3) \\
29172.38(-7) \\
33389.26(-1)\end{array}$ & 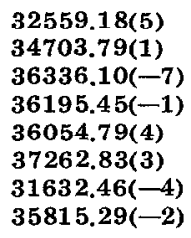 & $\begin{array}{l}\mathbf{3 0 3 4 7 . 4 1 ( 8 )} \\
31888.34(-4) \\
37320.49(-7) \\
37242.50(2) \\
37164.44(2) \\
38010.35(3) \\
29657.53(-5) \\
32680.70(1)\end{array}$ & $\begin{array}{c}33810.21(4) \\
35882.52(0) \\
- \\
35804.95(-1) \\
35678.39(1) \\
36836.70(0) \\
32904.99(-3) \\
36953.98(-1)\end{array}$ & 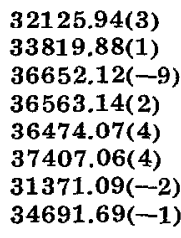 \\
\hline & $10-d_{1}$ & $6,7-d_{2}$ & $5,7-d_{2}$ & $6,7,8,9,10-\mathrm{d}_{5}$ & $5,7,8,9,10-d_{5}$ & \\
\hline $\begin{array}{l}2_{20}-2_{11} \\
2_{21}-2_{12} \\
3_{21}-2_{20} \\
3_{22}-2_{21} \\
3_{03}-2_{02} \\
3_{12}-2_{11} \\
3_{21}-3_{12} \\
3_{22}-3_{13}\end{array}$ & $\begin{array}{l}33886.23(4) \\
35931.46(0) \\
35775.14(-8) \\
35652.19(1) \\
35529.16(3) \\
36670.53(3) \\
32990.86(-3) \\
36988.39(-1)\end{array}$ & $\begin{array}{l}29170.58(7) \\
30751.19(0) \\
25679.21(-3) \\
35593.81(0) \\
35508.40(2) \\
36381.21(1) \\
28468.49(-6) \\
31565.35(-1)\end{array}$ & $\begin{array}{l}26939.97(3) \\
28546.53(-1) \\
36446.96(-3) \\
36351.51(3) \\
36255.99(1) \\
37151.43(-1) \\
26235.45(-3) \\
29376.46(0)\end{array}$ & $\begin{array}{l}27220.46(11) \\
28414.62(-8) \\
31069.15(-3) \\
31016.92(5) \\
30964.54(-2) \\
31612.27(0) \\
26677.20(-7) \\
29026.51(3)\end{array}$ & $\begin{array}{l}25343.83(12) \\
26559.70(-3) \\
31727.51(-3) \\
31669.32(1) \\
31611.11(2) \\
32275.34(0) \\
24795.83(-9) \\
27184.00(0)\end{array}$ & \\
\hline
\end{tabular}

${ }^{a}$ Values in parentheses are the observed minus calculated frequencies in $10 \mathrm{kHz}$.

${ }^{\mathrm{b}}$ See Fig. 1 for atom numbering.

\section{TABLE 2}

Moments of inertia $\left(u \AA^{2}\right)$ for propylene oxide ${ }^{a}$

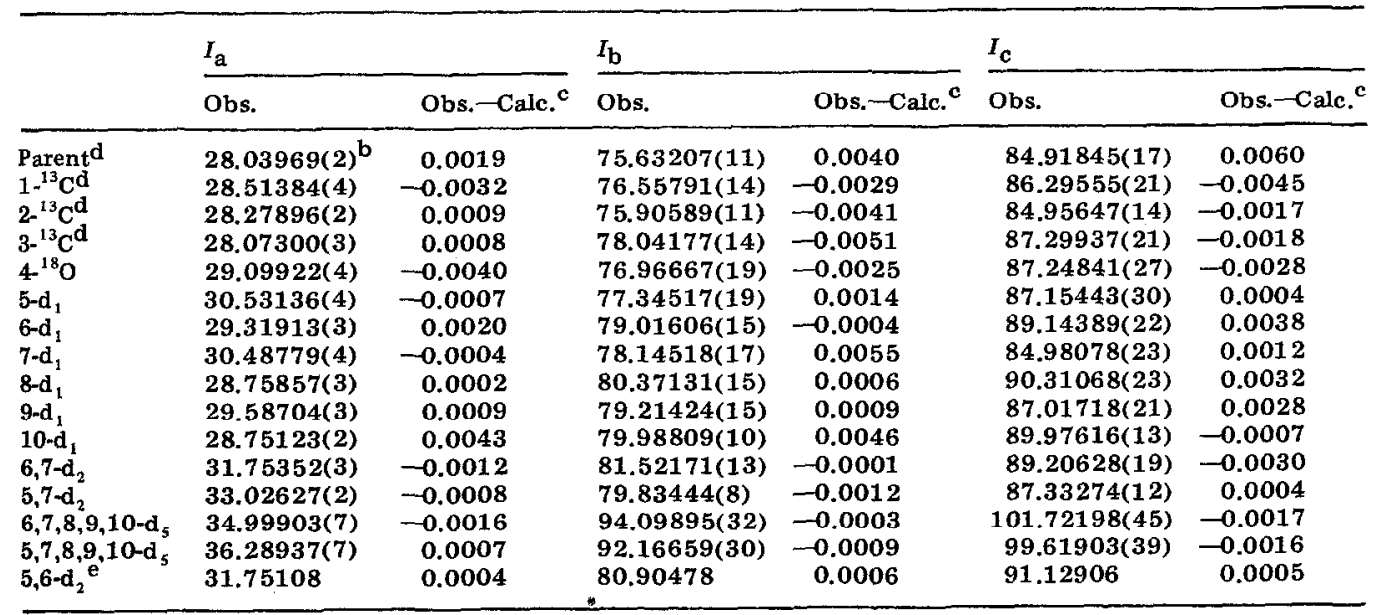

${ }^{\mathrm{a}} \mathrm{A}$ conversion factor of $505379.05 \mathrm{MHz}$ amu $\AA^{2}$ was used.

${ }^{b}$ The uncertainty is twice the standard deviation obtained from the least squares fit.

'Calc. values were obtained using the $r_{0}$ coordinates of Table 3 .

${ }^{\text {d} R e f . ~} 2$.

${ }^{e}$ Ref. 8. 
TABLE 3

Substitution and effective principal axes coordinates $(\AA)$ for propylene oxide

\begin{tabular}{|c|c|c|c|c|c|c|}
\hline & $a_{\mathrm{s}}^{\mathrm{a}}$ & $a_{0}$ & $b_{\mathrm{s}}$ & $b_{0}$ & $c_{\mathrm{s}}$ & $c_{0}$ \\
\hline C-1 & 0.9581 & 0.9612 & -0.6911 & -0.6943 & -0.1113 & -0.1151 \\
\hline C-2 & -0.1914 & -0.2101 & -0.0414 & -0.0447 & 0.4910 & 0.4917 \\
\hline C-3 & -1.5525 & -1.5550 & -0.0490 & -0.0483 & -0.1811 & -0.1846 \\
\hline 0.4 & 0.8108 & 0.8122 & 0.7369 & 0.7383 & -0.1372 & -0.1411 \\
\hline $\mathrm{H}-5$ & 0.8373 & 0.8388 & -1.1761 & -1.1772 & -1.0824 & -1.0825 \\
\hline $\mathrm{H}-6$ & 1.7653 & 1.7663 & -1.0566 & -1.0560 & 0.5103 & 0.5116 \\
\hline $\mathrm{H}-7$ & -0.2482 & -0.2492 & $0^{\mathrm{b}}$ & 0.0468 & 1.5744 & 1.5741 \\
\hline $\mathrm{H}-8$ & -2.1649 & -2.1654 & -0.8714 & -0.8717 & 0.1968 & 0.2001 \\
\hline H-9 & -1.4256 & -1.4265 & -0.1680 & -0.1693 & -1.2622 & -1.2625 \\
\hline H-10 & -2.0816 & -2.0827 & 0.8828 & 0.8846 & 0.0760 & 0.0115 \\
\hline
\end{tabular}

aThe signs of the $r_{\mathrm{s}}$ coordinates were chosen to agree with those of the $r_{0}$ coordinates.

${ }^{\mathrm{b}}$ Assumed.

TABLE 4

Structural parameters for propylene oxide and ethylene oxide ${ }^{a}$

\begin{tabular}{|c|c|c|c|c|c|c|c|}
\hline & $\begin{array}{l}\text { PRO } \\
r_{\mathrm{s}}\end{array}$ & $\begin{array}{l}\text { PRO } \\
r_{0}\end{array}$ & $\begin{array}{l}\text { ETO }^{\mathrm{b}} \\
r_{\mathrm{o}}\end{array}$ & & $\begin{array}{l}\text { PRO } \\
r_{\mathrm{s}}\end{array}$ & $\begin{array}{l}\text { PRO } \\
r_{0}\end{array}$ & $\begin{array}{l}\text { ETO } \\
r_{0}\end{array}$ \\
\hline$r\left(\mathrm{C}_{1} \mathrm{C}_{2}\right)$ & 1.451 & $1.470(3)^{\mathrm{c}}$ & $1.470(3)$ & $\angle \mathrm{H}_{5} \mathrm{C}_{1} \mathrm{O}_{4}$ & 114.5 & $114.4(2)$ & 114.8 \\
\hline$r\left(\mathrm{C}_{2} \mathrm{C}_{3}\right)$ & 1.518 & $1.505(2)$ & & $\angle \mathrm{H}_{6} \mathrm{C}_{1} \mathrm{O}_{4}$ & 115.0 & $114.8(1)$ & 114.8 \\
\hline$r\left(\mathrm{C}_{1} \mathrm{O}_{4}\right)$ & 1.436 & $1.441(2)$ & $1.434(2)$ & $\angle \mathrm{H}_{7} \mathrm{C}_{2} \mathrm{O}_{4}$ & 117.3 & $114.8(3)$ & 114.8 \\
\hline$r\left(\mathrm{C}_{2} \mathrm{O}_{4}\right)$ & 1.416 & $1.435(3)$ & $1.434(2)$ & $\angle \mathrm{H}_{5} \mathrm{C}_{1} \mathrm{C}_{2}$ & 118.7 & $118.3(1)$ & 119.2 \\
\hline$r\left(\mathrm{C}_{1} \mathrm{H}_{5}\right)$ & 1.092 & $1.088(2)$ & $1.085(4)$ & $\angle \mathrm{H}_{6} \mathrm{C}_{1} \mathrm{C}_{2}$ & 120.2 & $120.1(2)$ & 119.2 \\
\hline$r\left(\mathrm{C}_{1} \mathrm{H}_{6}\right)$ & 1.082 & $1.082(2)$ & $1.085(4)$ & $\angle \mathrm{H}_{7} \mathrm{C}_{2} \mathrm{C}_{1}$ & 118.2 & $118.5(3)$ & 119.2 \\
\hline$r\left(\mathrm{C}_{2} \mathrm{H}_{7}\right)$ & 1.086 & $1.087(1)$ & $1.085(4)$ & $\angle \mathrm{H}_{5} \mathrm{C}_{1} \mathrm{H}_{6}$ & 116.3 & $116.7(2)$ & 116.3 \\
\hline$r\left(\mathrm{C}_{3} \mathrm{II}_{8}\right)$ & 1.093 & $1.095(3)$ & & $\angle \mathrm{C}_{3} \mathrm{C}_{2} \mathrm{H}_{7}$ & 113.3 & $114.5(2)$ & \\
\hline$r\left(\mathrm{C}_{3} \mathrm{H}_{9}\right)$ & 1.095 & $1.092(2)$ & & $\angle \mathrm{C}_{2} \mathrm{C}_{3} \mathrm{H}_{8}$ & 110.7 & $110.0(3)$ & \\
\hline$r\left(\mathrm{C}_{3} \mathrm{H}_{10}\right)$ & 1.102 & $1.090(3)$ & & $\angle \mathrm{C}_{2} \mathrm{H}_{3} \mathrm{H}_{9}$ & 109.5 & $109.8(1)$ & \\
\hline$\angle \mathrm{O}_{4} \mathrm{C}_{1} \mathrm{C}_{2}$ & 58.7 & $59.1(2)$ & 59.2 & $\begin{array}{l}\angle \mathrm{C}_{2} \mathrm{C}_{3} \mathrm{H}_{10} \\
\angle \mathrm{H}_{8} \mathrm{C}_{3} \mathrm{H}_{9}\end{array}$ & $\begin{array}{l}108.8 \\
108.9\end{array}$ & $\begin{array}{l}110.5(4) \\
109.2(5)\end{array}$ & \\
\hline$\angle \mathrm{O}_{4} \mathrm{C}_{2} \mathrm{C}_{1}$ & 60.1 & $59.4(1)$ & 59.2 & $\angle \mathrm{H}_{9} \mathrm{C}_{3} \mathrm{H}_{10}$ & 112.2 & $109.2(8)$ & \\
\hline$\angle \mathrm{C}_{1} \mathrm{O}_{4} \mathrm{C}_{2}$ & 61.2 & $61.5(2)$ & 61.7 & $\angle \mathrm{H}_{10} \mathrm{C}_{3} \mathrm{H}_{8}$ & 106.7 & $108.1(3)$ & \\
\hline$\angle \mathrm{C}_{1} \mathrm{C}_{2} \mathrm{C}_{3}$ & 121.6 & $121.7(2)$ & & & & & \\
\hline \multirow[t]{4}{*}{$\angle \mathrm{O}_{4} \mathrm{C}_{2} \mathrm{C}_{3}$} & 116.2 & $116.1(2)$ & & $\tau\left(\mathrm{O}_{4} \mathrm{C}_{2} \mathrm{C}_{3} \mathrm{H}_{9}\right)^{\mathrm{d}}$ & -44.1 & $-44.0(5)$ & \\
\hline & & & & $\tau\left(\mathrm{C}_{1} \mathrm{C}_{2} \mathrm{C}_{3} \mathrm{H}_{9}\right)$ & 25.4 & $24.7(8)$ & \\
\hline & & & & $\tau\left(\mathrm{C}_{1} \mathrm{C}_{2} \mathrm{C}_{3} \mathrm{H}_{8}\right)$ & -94.7 & $-95.5(5)$ & \\
\hline & & & & $\tau\left(\mathrm{C}_{1} \mathrm{C}_{2} \mathrm{C}_{3} \mathrm{H}_{10}\right)$ & 148.4 & $145.2(12)$ & \\
\hline
\end{tabular}

aBond lengths are in $\AA$ and bond angles are in degrees.

${ }^{b}$ Ref. 12.

'The values in parentheses are one standard deviation in the fit and refer to the last digits given.

d The dihedral angles are defined in ref. 14. 


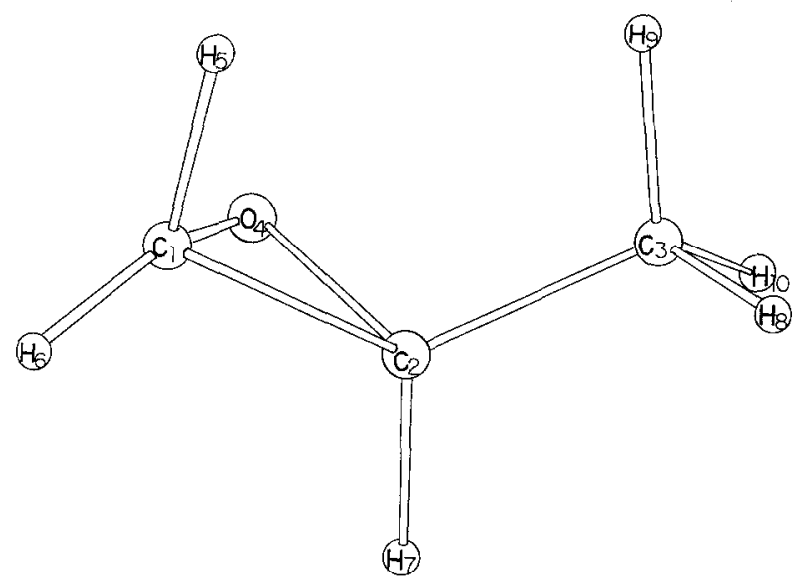

Fig. 1. Atom numbering scheme for propylene oxide.

coordinates of this magnitude are obtained from a Kraitchman analysis. Consequently, propylene oxide is not an exemplary case for determination of accurate parameters by this method.

The data set of 16 isotopes ( 48 moments of inertia) is diverse enough to determine a $r_{0}$ structure ( 24 internal structural parameters) by a least-squares fitting iteration without any assumed structural parameters [10]. These principal axes coordinates (the effective or $a_{0}$ etc. values) are in Table 3 and the $r_{0}$ structural parameters are in Table 4 . Table 2 lists the values of $I_{\text {obs. }}-I_{\text {calc. }}$ $\left(\mathrm{rms}=0.0036 \mathrm{u} \AA^{2}\right)$ which indicates the quality of the least-squares fit.

It is noted that the agreement between the substitution and effective coordinates (Table 3 ) is very good except for three small coordinates: $a\left(\mathrm{C}_{2}\right)$, $b\left(\mathrm{H}_{7}\right)$, and $c\left(\mathrm{H}_{10}\right)$. However, it is also apparent that the least-squares fitting procedure which employs all the data has excellent consistency in reproducing the observed moments of inertia. It is not easy to ignore this consistency which seems to imply that the problem of small coordinates is minimized via such an analysis. Presumably, this occurs by distributing the vibrationrotation effects over the entire data set so that they do not concentrate in any single structural parameter. For these reasons, as well as the good agreement with ethylene oxide (see below), the $r_{0}$ parameters are the preferable set. These $r_{0}$ parameters are probably close to the so called $r_{\mathrm{z}}$ or average structure $[11,12]$. Uncertainty limits of $\pm 0.01 \Lambda$ and $\pm 0.5^{\circ}$ attached to the $r_{0}$ parameters are likely to be sufficient to encompass the $r_{\mathrm{z}}$ parameters except for the dihedral angles involving the methyl hydrogen atoms with the ring where an uncertainty of $\pm 3^{\circ}$ is recommended.

These results can be compared to the $r_{0}$ parameters previously estimated for ethylene oxide [12] (see Table 4). Ethylene oxide is a favorable species to determine $r_{0}$ (or $r_{\mathrm{s}}$ ) parameters since all non-zero atom coordinates are at least $\pm 0.4 \AA$. It is seen that the perturbation of the ethylene oxide framework 
by the methyl group has only minor structural consequences. The methyl group itself in the $r_{0}$ fit has nearly $C_{3}$ symmetry about the $\mathrm{C}_{3} \mathrm{C}_{2}$ bond axis and standard parameter values. Because vibration-rotation effects are not rigorously accounted for in both the $r_{0}$ and $r_{\mathrm{s}}$ structure calculations and because of three small $\mathrm{H}$ coordinates, it is not possible to be certain whether the methyl group has nearly exact $C_{3}$ local symmetry in the equilibrium structure or whether the small asymmetry or tilt suggested by the $r_{\mathrm{s}}$ structure is significant. Nevertheless, the $r_{0}$ results, for the reasons mentioned above, lead us to conclude that there exists little asymmetry. The methyl group dihedral angles ( $\tau$ values) are interesting since few have been determined for $\mathrm{CH}_{3}$ attached to a three-membered ring. These values of $\tau$ are the least accurately known parameters but it is clear that the $\mathrm{C}_{3}-\mathrm{H}_{9}$ bond does not symmetrically straddle the $\mathrm{OC}_{2} \mathrm{C}_{1}$ plane. Although $\mathrm{H}_{9}$ appears to rotate towards the $\mathrm{C}_{1}$ atom, given the $\tau$ values in Table 4, it is actually $0.036 \AA$ closer to $\mathrm{O}_{4}$ than $\mathrm{C}_{1}$.

The previous $r_{0}$ results [2] for PRO had a large estimated uncertainty range $\left(0.01-0.02 \AA, 0.5-1.3^{\circ}\right)$ which was sufficient to encompass the new results. More extensive comparisons of the structural parameters with other epoxides and three-membered rings may be found in the literature $[12,13]$.

\section{ACKNOWLEDGEMENTS}

The authors acknowledge the assistance of Dr. Alexander Lopata, Dr. Kurt Hillig and Mr. Donald Borseth in aspects of this study. We are also grateful to the donors of the Petroleum Research Fund, administered by the American Chemical Society, for support of this work. The National Science Foundation (Washington, D.C.) provided funds to purchase and maintain the microwave spectrometer.

\section{REFERENCES}

1 J. D. Swalen and D. R. Herschbach, J. Chem. Phys., 27 (1957) 100.

D. R. Herschbach and J. D. Swalen, J. Chem. Phys., 29 (1958) 761.

2 R. A. Creswell and R. H. Schwendeman, J. Mol. Struct., 64 (1977) 295.

3 M. Imachi, M. Egashira, R. L. Kuczkowski and N. W. Cant, J. Catal., 70 (1981) 177.

4 D. J. Pasto and C. C. Cumbo, J. Org. Chem., 30 (1965) 1277.

5H. C. Brown, E. F. Knights and C. G. Scouten, J. Am. Chem. Soc., 96 (1974) 7765;

H. C. Brown and G. Zweifel, J. Am. Chem. Soc., 83 (1961) 3834.

6 C. D. Hurd and J. L. Azorlosa, J. Am. Chem. Soc., 73 (1951) 33.

7 R. McCullough and F. Cortese, J. Am. Chem. Soc., 51 (1929) 225.

8 S. S. Butcher, PhD Dissertation, Harvard University, 1962.

9 J. Kraitchman, Am. J. Phys., 21 (1953) 17.

10 R. H. Schwendeman, in D. R. Lide and M. A. Paul (Eds.), Critical Evaluation of Chemical and Physical Structural Information, National Academy of Sciences, Washington, D.C., 1974, p. 74 .

11 V. W. Laurie and D. R. Herschbach, J. Chem. Phys., 37 (1962) 1687.

12 C. Hirose, Bull. Chem. Soc. Jpn., 47 (1974) 1311.

13 C. W. Gillies, J. Mol. Spectrosc., 71 (1978) 85.

14 E. B. Wilson, Jr., J. C. Decius and P. C. Cross, Molecular Vibrations, McGraw-Hill, New York, 1955, p. 60. 